\title{
Congenital fibre type disproportion with unusual clinico-pathologic manifestations
}

\author{
AR SULAIMAN, ${ }^{*}$ HERBERT M SWICK, $\dagger$ DEBRA S KINDER \\ From the Department of Neurology, Veterans Administration Medical Center* and Milwaukee Childrens \\ Hospital, $\dagger$ Medical College of Wisconsin $\ddagger$
}

SUMmaRY Two cases with congenital fibre type disproportion are presented. The cases are unusual in that there were significant dysmorphic features in case 1 , and both cases showed electromyographic abnormalities suggestive of denervation. A third case, the father of the second patient, showed clinical features of congenital fibre type disproportion in early life but later developed the rigid spine syndrome. The spinal cord of case 3 showed atrophy and degeneration of medial neuronal group in the lumbosacral segments. The clinical and pathological features in these cases further extend the view that congenital fibre type disproportion may be seen in a variety of patients.

In 1973, Brooke ${ }^{1}$ described a group of 12 patients with hypotonia and delayed motor milestones who, in addition, showed small height and weight, contractures, spine deformity and congenital hip dislocation. In addition to being floppy at birth, these children showed varying degrees of weakness which appeared most severe in the initial stages of development. Their muscle biopsies showed atrophy or relative hypotrophy of Type I fibres with or without hypertrophy of Type II fibres. Based on the findings of muscle biopsy, Brooke ${ }^{1}$ reported these cases as congenital fibre type disproportion. Skeletal abnormalities, although seen in some cases, are not considered a hallmark of the disease process. None of these patients showed evidence of myotonic dystrophy, cerebellar disease or the scapuloperoneal syndrome. Despite the label "congenital", patients with congenital fibre type disproportion may be asymptomatic or may note the onset of symptoms during early childhood. The disease is not always benign since at least four deaths have occurred ${ }^{2}{ }^{3}$ and associated defects are common. Although the clinical features reported in several of the initial series were somewhat stereotyped, more recent reports indicate that varied clinical features such as "rigid spine" 5 and "static encephalopathy" may occur. Electro-

Address for reprint requests: AR Sulaiman, FRCP(C), Department of Neurology, Veterans Administration Medical Center, 5000 West National Avenue, Wood, Wisconsin 53193, USA.

Received 30 June 1982

Accepted 1 October 1982 myography is usually described as normal or myopathic $^{1-9}$ and very rarely neurogenic. ${ }^{10}$ Serum muscle enzymes are seldom elevated.

The term "fibre type disproportion", strictly, could include any fibre type disproportion. ${ }^{8}$ However, we use it here in the context as described originally by Brooke. ${ }^{1}$ Congenital Type I fibre atrophy or hypotrophy is distinct from Type II fibre atrophy, which is usually a nonspecific finding seen in such varied states as pyramidal tract disease, collagen vascular disease, myasthenia gravis, after steriod therapy and disuse atrophy. ${ }^{11}{ }^{12}$ In contrast to the Type I fibre atrophy or hypotrophy, cases with Type II fibre hypotrophy in infancy are considered to have less severe disabilities. ${ }^{3}$

In this report we describe three patients with congenital fibre type disproportion. The cases are unusual in that they showed neurogenic changes in the EMG. Case 3 had type grouping in the temporalis muscle and evidence of cardiomyopathy at necropsy. Dysmorphic features of case 1 further extend the view that congenital fibre type disproportion may be seen in a wide variety of patients and that the diagnosis in some cases remains at best pathological.

\section{Case reports}

Case 1

A 16-month-old white male presented with delayed motor development. He was born at term following an uncomplicated pregnancy and delivery. In early infancy he required several hospitalisations for recurrent respiratory difficulties and pneumonitis. At age 6 weeks he was noted to 
be hypotonic with head lag. Cry was somewhat weak although there was a good suck. Mildly dysmorphic features included an upturned tip of the nose and a long lingual frenulum with relative micrognathia. By age 14 months, he could stand with support, but head lag persisted with generalised hypotonia, most marked proximally. He moved all extremities well against gravity. The reflexes were diminished in the upper extremities and absent in the lower extremities. Speech consisted only of two or three single words. Chromosome studies were normal. Routine laboratory studies were unremarkable, including muscle enzymes. Nerve conduction velocities were normal, but needle electromyography showed positive sharp waves. There were bizarre high frequency discharges with activity. Occasional giant units occurred with increasing activity and occasional fibrillation potentials persisted for many seconds after activity.

\section{Case 2}

A 4-year-old girl had mild muscle weakness. She was born following a normal pregnancy. Early developmental milestones were unremarkable, but parents noted weakness when she started walking, especially if she tried to climb stairs or to run. At age $2 \frac{1}{2}$ years, evaluation showed marked proximal weakness; this improved over the subsequent two years. With this improvement, mobility and general strength also improved, so that examination at age four years showed only mild proximal weakness without specific atrophy. Reflexes were depressed throughout. There was no scoliosis or other skeletal abnormalities. Intelligence was normal. Laboratory evaluation showed mild elevations in creatine kinase (597 IU; normal: 8-138 IU) and aldolase (1.225; normal: $0.284-0.6 \mathrm{mcg} / \mathrm{ml})$. Electromyography showed sustained positive sharp waves with fibrillation potentials. Amplitudes were moderately increased. Nerve conduction velocities were normal. Findings were indicative of chronic neurogenic changes.

\section{Case 3}

The 32-year-old father of case 2 had a history of progressive neuromuscular disease since infancy. He began to walk at about 12 months of age but was never able to run. A diagnosis of "muscular dystrophy" was made at 18 months of age. By age 10, he was walking on his toes; by age 13 he required crutches, and shortly thereafter he was using a wheelchair. At age 16 he developed severe flexion contractures in his neck muscles. He sustained a cord injury during laminectomy and became quadriplegic. He subsequently had three attempts at surgical fusion to stabilise his cervical spine. He recovered some function and was able to ambulate on parallel bars, but further progression occurred and he became wheelchair bound at age 30 . Examination showed intact cranial nerves. He had multiple flexion contractures of the shoulders, elbows, wrists, fingers, hips, knees and ankles. There was a fixed lumbar lordosis and dorsal kyphosis. Muscle strength was difficult to evaluate because of the severe contractures. Deep tendon reflexes were absent, and sensory examination was normal. At age 32 he developed pneumonia, respiratory difficulties and cardiac failure, which led to his death.

\section{Methods}

Gastrocnemius muscle in case 1 , quadriceps muscle in case 2 and temporalis muscle of case 3 were processed for cryostatsections. ${ }^{12}$ Sections of the muscle $(8 \mu \mathrm{m}$ thick) were studied with haematoxylin-eosin (H\&E), modified trichrome stain, ${ }^{13}$ adenosine triphosphatase (ATP, at pH 9.4, 4.6 and $4 \cdot 3),{ }^{14}$ reduced diphosphopyridine nucleotide diaphorase (DPNH), succinic dehydrogenase (SDH), periodic acid Schiff (PAS) and oil red "O" stain. Formalin fixed paraffin embedded sections of the sternomastoid, diaphragm and heart (case 3 ) were studied with $H \& E$ and trichrome stain. From the muscle biopsy sections stained with ATP, photographs were made of representative areas of muscle for measurement of fibre size, standard deviations (SD) and relative frequencies of muscle fibre types. Sural nerve biopsies of case 1 and 2 and necropsy sections of portions of the cerebral cortex, brainstem and portions of the spinal cord of case 3 were studied with $H \& E$, trichrome, luxol fast blue, toluidine blue, and Bielschowski stains. Portions of the sural nerves of case 1 and 2 and the anterior and posterior dorsal and lumbosacral spinal nerve roots of case 3 , were stained with osmic acid for teased fibre preparations.

\section{Results}

\section{Case 1}

In the H\&E and trichrome stain of the gastrocnemius muscle there was random variation in fibre sizes. The muscle fibres were polygonal. The nuclei were unremarkable in number and distribution pattern. There were no significant architectural abnormalities. Connective tissue was of normal amount. A couple of muscle spindles were present and these showed some thickening of the capsule. Intramuscular nerve segments were normal. Histochemically, the majority of the largest fibres were of Type II. With subtyping, most of these were

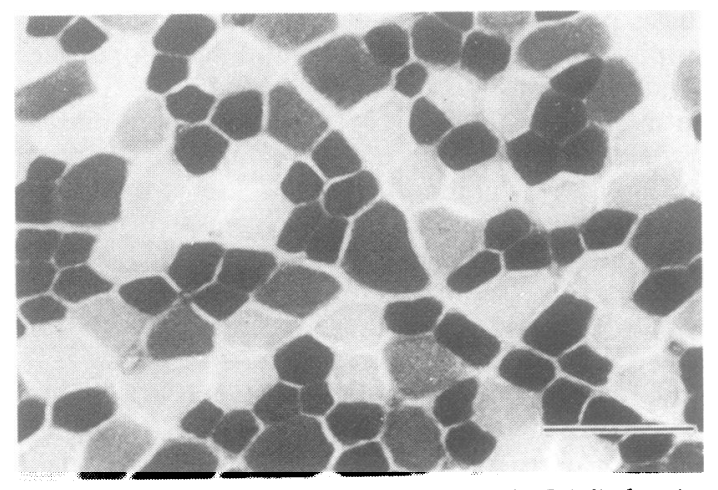

Fig 1 Case 1. Deltoid muscle. ATP stain (pH 4.6) showing hypotrophy of Type I fibres and Hypertrophic Type II-A (pale) and Type II-B (intermediate staining) fibres. Bar measures 50 um in this and other photomicrographs. 
Table 1 Fibre size and type distributions

\begin{tabular}{|c|c|c|c|c|c|c|c|c|c|c|c|}
\hline & \multirow[t]{2}{*}{ Age } & \multirow[t]{2}{*}{ Muscle } & \multicolumn{2}{|c|}{ Type I fibre } & \multicolumn{2}{|c|}{ Type II-A fibre } & \multicolumn{2}{|c|}{ Type II-B fibre } & \multicolumn{3}{|c|}{ Percentage of fibre type } \\
\hline & & & $\begin{array}{l}\text { Mean } \\
\text { diameter } \\
(\mu \mathrm{m})\end{array}$ & $S D$ & $\begin{array}{l}\text { Mean } \\
\text { diameter } \\
(\mu \mathrm{m})\end{array}$ & $S D$ & $\begin{array}{l}\text { Mean } \\
\text { diameter } \\
(\mu \mathrm{m})\end{array}$ & $S D$ & $I$ & $I I A$ & $I I B$ \\
\hline $\begin{array}{l}\text { Case } 1 \\
\text { Case } 2 \\
\text { Case } 3\end{array}$ & $\begin{array}{l}16 \text { months } \\
4 \text { years } \\
32 \text { years }\end{array}$ & $\begin{array}{l}\text { Gastrocnemius } \\
\text { Quadriceps } \\
\text { Temporalis }\end{array}$ & $\begin{array}{l}16 \cdot 00 \\
23 \cdot 23 \\
29 \cdot 30\end{array}$ & $\begin{array}{l}3 \cdot 78 \\
6 \cdot 84 \\
9 \cdot 10\end{array}$ & $\begin{array}{l}18 \cdot 15 \\
34 \cdot 85 \\
15 \cdot 79\end{array}$ & $\begin{array}{l}3 \cdot 33 \\
6 \cdot 27 \\
5 \cdot 21\end{array}$ & $\begin{array}{l}20 \cdot 46 \\
38 \cdot 72 \\
14 \cdot 38\end{array}$ & $\begin{array}{l}2 \cdot 90 \\
5 \cdot 73 \\
5 \cdot 01\end{array}$ & $\begin{array}{l}49 \\
68 \\
69\end{array}$ & $\begin{array}{r}26 \\
24 \\
6\end{array}$ & $\begin{array}{r}25 \\
8 \\
25\end{array}$ \\
\hline
\end{tabular}

$\mathrm{SD}=$ standard deviation.

of Type II-B. Type I fibre diameter ranged from 6 to $22 \mu \mathrm{m}$ while Type II-A and II-B fibres ranged from 14 to $23 \mu \mathrm{m}$ and 11 to $29 \mu \mathrm{m}$ respectively. The mean diameter of Type I fibres were smaller than the mean diameter of Type II-B fibres by at least $12 \%$ (table 1 ). Other histochemical reactions were unremarkable. The muscle biopsy findings were consistent with congenital fibre type disproportion. Sural nerve biopsy showed no significant abnormality.

\section{Case 2}

As in case 1 , in the $H \& E$ and trichrome stain two sizes of muscle fibres could be distinguished clearly. There were several degenerating fibres and some of these were undergoing myophagia. There were also a few regenerating fibres. Sarcolemmal nuclei were unremarkable. Internal nucleation was not excessive. Connective tissue was of normal amount. In the ATP stain, there was moderate Type I fibre preponderance (table 1). Type I fibres ranged from 18-36 $\mu \mathrm{m}$ in diameter while Type II-A and II-B fibres ranged from 31 to $45 \mu \mathrm{m}$ and 27 to $45 \mu \mathrm{m}$ respectively. Mean Type II-B fibre diameter (fig 2) was larger than the mean Type I fibre diameter by over $12 \%$. Other histochemical reactions were unremarkable. The muscle biopsy findings were consistent with congenital fibre type disproportion.

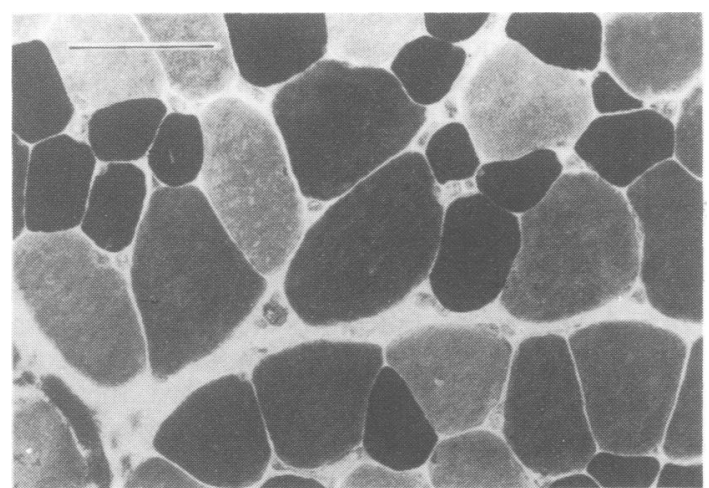

Fig 2 Case 2. Quadriceps muscle biopsy. ATP stain (pH 4.6). The darker staining Type I fibres are markedly smaller as compared to the Type II-A fibres (paler staining) and Type II-B fibres (intermediate staining).
Sural nerve biopsy showed no significant abnormality.

Case 3

Temporalis muscle showed random variation in fibre sizes with presence of many atrophic fibres. A number of the atrophic fibres appeared to have rounded borders. Angulated atrophic fibres were rare. In the H\&E stain, many atrophic fibres showed a somewhat deeper staining reaction. No hypertrophic fibres were seen. There were several degenerating fibres (fig 3). Internal nucleation was mildly excessive. Focal areas also showed some increase in endomysium. At times, there were rare perivascular mononuclear cell infiltrations. In the histochemical stains, there was atrophy and hypotrophy of both fibre types, the atrophy being pronounced and more prevalent in Type II fibres (fig 4). The abnormalities were not uniform in all areas and some regions showed suggestive fibre type grouping. In focal areas, some fascicles consisted of uniformly smaller size fibres. Similarly, the preponderance of fibre types also varied from region to region but in most areas Type I fibres were seen in greater numbers. With oxidative enzymes, there were a few moth-eaten fibres and some of the atrophic fibres were darker or intermediately deeper staining. Sternomastoid muscle showed an overall dystrophic appearance with presence of atrophic and

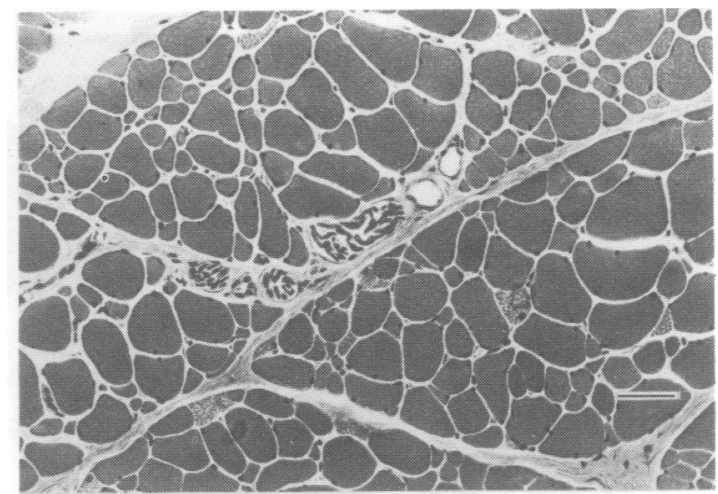

Fig 3 Case 3. Temporalis muscle. H\&E stain showing variation in fibre sizes and several degenerating fibres. 


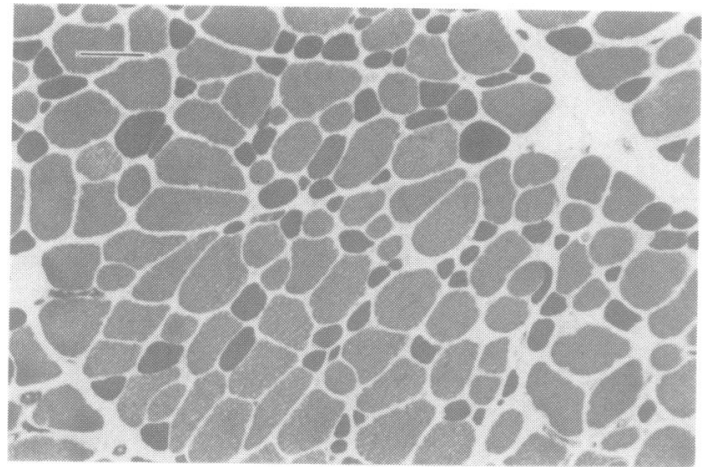

Fig 4 Case 3. Temporalis muscle. ATP stain ( $\mathrm{pH}$ 9.4) showing atrophic fibres of both fibre types, Type I fibre preponderance and relatively small Type II fibres.

hypertrophic fibres, fibre necrosis and loss with fibrofatty tissue replacement. In focal areas, internal nucleation was excessive. There were a few regenerating fibres and fibres showing whorling and snake coiled appearance. Formalin-fixed tissue of the diaphragm (fig 5) showed many atrophic fibres. There were several degenerating fibres. Some regenerative activity was present. Considerable fibrofatty tissue replacement was seen in focal areas. Heart muscle (fig 6) showed generally thin myocardial fibres. Loosening of myofibrils and a rarefied appearance was common. The number of nuclei appeared increased. In many fibres, the perinuclear halo was enlarged and contained increased pigment deposit. Some fibres showed floccular degeneration. Portions of the cerebral cortex and white matter showed no significant abnormality. In the brainstem, there was some suggestion of decrease in the number of neurons in the fifth nerve nucleus (upper third of pons) and dorsal motor nucleus of vagus (middle third of medulla) accompanied with astrocytic proliferation. However, these abnormalities were considered very mild. Only a small portion of the

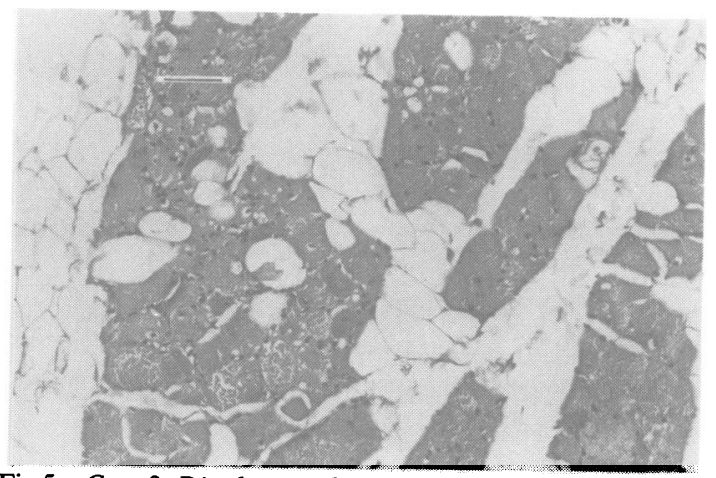

Fig 5 Case 3. Diaphragm showing degenerating muscle fibres and large accumulation of fatty tissue. $H \& E$ stain.

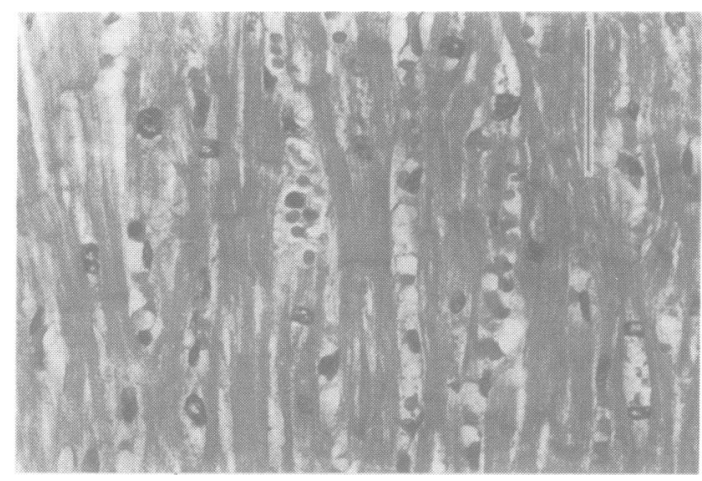

Fig 6 Case 3. Myocardium showing atrophic and degenerating fibres. Many nuclei are hyperchromatic and surrounded by larger perinuclear halo which often showed some pigment accumulation. $H \& E$ stain.

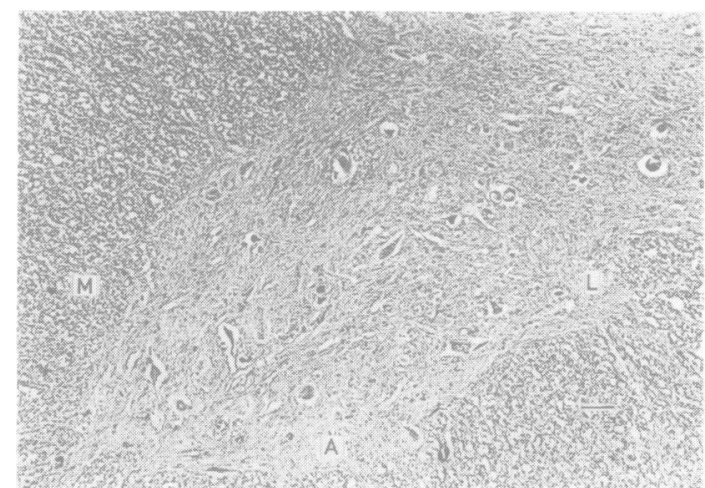

Fig 7 Case 3. Upper dorsal spinal cord. Anterior horn. Note atrophic and shrunken neurons. $H \& E$ stain. $M=$ medial, $L=$ lateral and $A=$ anterior $z$ zones of the cord.

uppermost cervical spinal cord was available. Here there was loosening of the structures and some gliosis was observed in the corticospinal tracts. Sections from the mid and upper dorsal regions of the spinal cord (fig 7) showed sparse neuronal population, many of which were of small size and shrunken. Some astrocytic proliferation was present. Bilaterally asymmetric loss of myelin of slight to moderate degree with gliosis was noted in the corticospinal tracts. The central region of the posterior columns also showed some rarefaction. Involvement of the corticospinal tracts and the posterior columns was minimal in the lumbosacral regions of the cord. However, in these segments of the cord, there was moderate decrease in the number of neurons in the medial zones of the anterior horns. The remaining neurons in the medial zones of anterior horns were shrunken or atrophic (figs 8 and 9). A few showed anoxic change. Some reactive astrocytes were present. Neurons in the lateral zones of anterior horn 


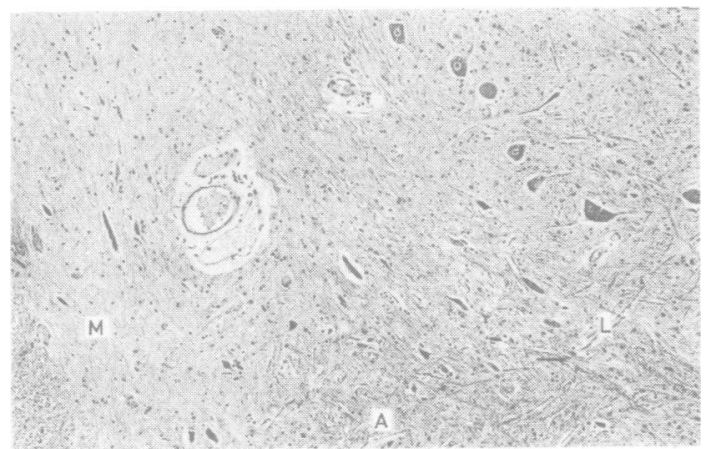

Fig 8 Case 3. Mid lumbar region of the spinal cord showing shrunken and atrophic neurons in the medial groups of anterior horns and some reactive astrocytosis. H\&E stain.

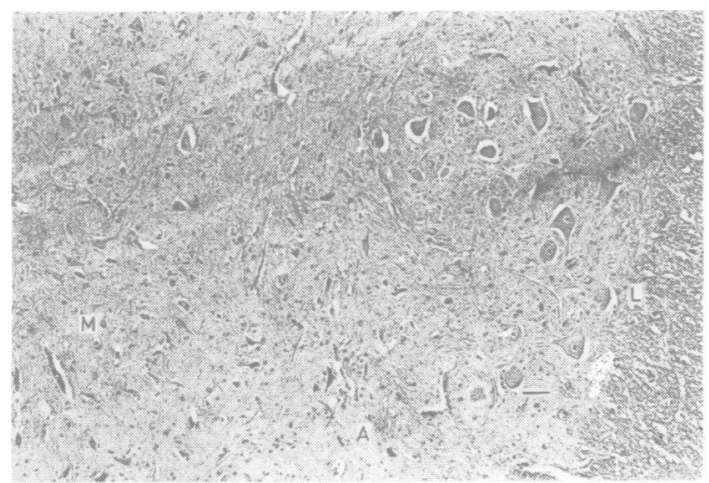

Fig 9 Case 3. Sacral spinal cord showing atrophic medial group of neurons in the anterior horn and some reactive astrocytosis. $H \& E$ stain.

were unremarkable. The nerve roots showed no significant abnormality. Some fibres of the anterior nerve roots from the lumbosacral region showed some decreased thickness of myelin and rarely demyelination.

\section{Discussion}

The three cases presented here with symptoms and signs of a "congenital myopathy" showed unusual muscle biopsy findings. Case 1 and 2 showed congenital fibre type disproportion as described by Brooke. ${ }^{1}$ The clinical features in case 2 are quite similar to patients in Brooke's original case report while case 1 showed several other dysmorphic features. Case 3 did not have findings typical of congenital fibre type disproportion but the findings were complicated by spinal cord injury.

In several reports of patients with congenital fibre type disproportion, there is a family history of a neuromuscular disease in another member of the
Table 2 Congenital fibre type disproportion (29 patients) clinical features

\begin{tabular}{lr}
\hline Onset: At birth or shortly thereafter & 17 \\
$\quad$ First year & 5 \\
Second year & 2 \\
Five to ten years & 2 \\
Decreased height & 8 \\
Small weight & 13 \\
Hypotonia/floppy & 17 \\
High arch palate & 9 \\
Scoliosis & 12 \\
Contractures & 10 \\
Congenital hip dislocation & 4 \\
Delayed motor milestone & 13 \\
\hline
\end{tabular}

same family. The syndrome has been reported in identical twins ${ }^{15}$ and has been transmitted as an autosomal dominant trait. ${ }^{8}{ }^{16}{ }^{17}$ Our case 2 suggests autosomal dominant inheritance.

Clinical manifestations associated with this syndrome have been well documented ${ }^{1}$ and are summarised in table 2 . The majority of cases are symptomatic at birth or shortly thereafter. Delayed motor milestones secondary to diffuse or predominantly proximal weakness and hypotonia are features common to many congenital myopathies. In fact to distinguish congenital fibre type disproportion from other congenital myopathies solely on the clinical manifestations is extremely difficult, if not impossible. Involvement of the face and palate, deformity of spine and foot, and hip dislocations occur also in other congenital myopathies. The distinctive facial appearance of case 1 initially was felt to be a $4 p$ syndrome, but chromosomal studies were normal. Developmental evaluation showed psychomotor retardation. A similar facial appearance was noted in the mother, who did not have any clinical evidence of myopathy but whose EMG showed myopathic changes in proximal muscle groups. She refused permission for a muscle biopsy. Of interest in this regard is a case of congenital fibre type disproportion described by Clancy et $a^{6}$ who showed, in addition to hypotonia, diffuse weakness with inadequate head control, peculiar facies, protuberant abdomen, abnormal lanugo hair, joint laxity and seizures. Development lagged in all spheres. Recurrent respiratory infections as seen in our case 1 were present in several of the original cases. The cause of this is not known.

Electromyography in two of these cases suggested denervation. In previous cases, the EMG was reported as normal or showing only mild nonspecific myopathic features. ${ }^{17-9}$ Very rarely have there been descriptions of neurogenic abnormalities..$^{10}$

Muscle biopsy in cases 1 and 2 showed no significant increase in internal nuclei. Type I fibre preponderance was present in case 2 . In both cases the mean diameter of Type II fibres was significantly 
large and the largest fibres were of Type II-B. In both these cases there were many normal sized Type I fibres. In Brooke's ${ }^{1}$ series, only four cases out of $\mathbf{1 2}$ had significant reduction in the mean fibre diameter of Type I fibres. In a review of the pathological reports in 29 cases (table 3 ) 18 cases showed normal

Table 3 Congenital fibre type disproportion (29 patients). Muscle biopsy findings

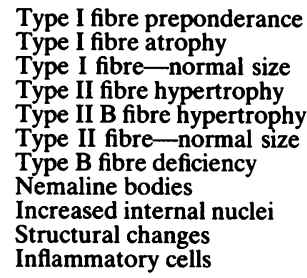

sized Type I fibres. Type II fibre hypertrophy was mentioned in only nine cases. Type II-B fibre hypertrophy was noted in four cases. Four cases had deficiency of Type II-B fibres. Nemaline bodies or other structural changes and inflammatory response were rare.

Although the initial symptoms in case 3 were similar to classical congenital fibre type disproportion, later progression was considered more akin to the rigid spine syndrome. There are at least two instances of rigid spine syndrome with congenital fibre type disproportion. ${ }^{45}$ One of the original cases of Brooke ${ }^{1}$ was noted to develop rigid spine..$^{18}$ It may be postulated that some of the neuromuscular disabilities in case 3 were related to the injured spinal cord following laminectomy; however, we suspect that the later development of contractures in all his extremity joints was at least partially related to or aggravated by his muscular disease.

Because of the old injury to the cervical cord, we chose to study the temporalis muscle rather than one of the extremity muscles. The results were quite surprising. There were a number of degenerating fibres, with changes seen predominantly in the atrophic or smaller sized fibres. Some of the atrophic fibres showed angulation. However, such fibres were distinctly few in number. The majority of the atrophic fibres had some rounding of the borders. The appearance in some areas was quite like childhood spinal muscular atrophy. With histochemical stains, the atrophy and hypotrophy affected both fibre types, the Type II fibres being markedly affected. Deficiency of Type II-A fibres was associated with preponderance of Type I fibres. In focal areas there was suggestive fibre type grouping.
In a study of human masticatory muscles, Ringqvist ${ }^{19}$ found there was no statistically significant difference between muscle fibre size in males and females, and the two fibre types had generally smaller diameter than the corresponding fibre types of limb muscles. In 10 out of 12 specimens, the Type II fibres dominated in number and averaged $65 \%$. However, in one of their cases, the temporalis and masseter muscle (their fig 1C) showed slight to marked difference between the two fibre sizes and preponderance of Type I fibres, an appearance not unlike that seen in focal areas in our patient. Recently, Vignon, Pellissier and Serratrice ${ }^{20}$ have confirmed the findings of Ringqvist. ${ }^{19}$ Their findings show that adult masticatory muscles have a markedly increased number of Type II fibres and a disparity in the size of two main fibre types, the Type II fibres being about half the size of Type I fibres. In the adult temporalis muscle, the Type I fibres ranged from 10 to $70 \mu \mathrm{m}$ (average $35 \mu \mathrm{m}$ ) and the Type II fibres ranged from 10 to $60 \mu \mathrm{m}$ (average $18.3 \mu \mathrm{m}$ ) in diameter. All the fibres were generally round or oval. They attributed the difference in size between the fibre types to the physiology of mastication. In our case the Type II fibres were of half the size of Type I but the fibre type preponderance was of Type I.

Other muscles of case 3 showed severe changes. The sternomastoid muscle was extensively replaced by fibro-fatty tissue. Most regions showed dense connective tissue bands with no muscle fibre. Several segments of intramuscular nerves appeared unremarkable. In the diaphragm, there were many atrophic fibres distributed in a random fashion. There were numerous degenerating fibres. Some regenerative activity was evident from basophilia of the cytoplasm and the presence of large vesicular nuclei. The muscle fascicles were generally small and widely separated by fatty tissue. Connective tissue proliferation was only moderate. Although it may be argued that the pathological changes in these muscles were related to trauma to the cord, we suspect that these changes were primary, that is related to the disease process, as there was no mention of respiratory difficulty specifically resulting from the trauma to the cervical cord. Moreover, normally, these muscles are innervated from the upper segments of the cervical cord. In 1977, De Reuck et al, ${ }^{2}$ described a 21-month-old boy with respiratory paralysis who showed at necropsy extensive degeneration of the diaphragm and intercostal muscles. Although clinically they felt the case to be quite different from congenital fibre type disproportion, histoenzymatic examination of the extremity muscles showed relative atrophy of Type I fibres with hypertrophy of Type II fibres. The spinal cord did not show any significant neuronal loss and the phrenic nerves 
appeared normal. Respiratory difficulties during early childhood in some patients with congenital fibre type disproportion may be related to the degenerative changes in the respiratory muscles. There were also abnormalities in the myocardium of case 3. Several fibres showed atrophy and degeneration with nuclear proliferation in several areas showing degeneration. Many fibres contained a pigmentary deposit. There is no previous report of myocardiopathy associated with congenital fibre type disproportion. Although the patient described by De Reuck et al showed tachycardia, heart muscle was normal.

To our knowledge, there are no reports of neuronal abnormalities in congenital fibre type disproportion. Evaluation of the sections of the spinal cord in case 3 showed asymmetric involvement of corticospinal tracts in the upper dorsal segments. This was attributed to the cervical cord injury sustained at age 16. Corticospinal tract involvement was minimal in the lumbosacral region. However, there was a decrease in neuronal population in the medial zones of the anterior horns in the lumbosacral segments. The remaining neurons (medial zones of the anterior horn) in the lumbosacral segments and in the anterior horn of dorsal (thoracic) segments appeared shrunken and atrophic. Neurons in the lateral zone of the lumbosacral region appeared unremarkable. Many ${ }^{21-23}$ believe that the medial neuronal groups in the anterior horn innervate the paraspinal and other axial muscles. The medial neuronal group may be sparse or infrequent in appearance and may even be absent in some normal spinal cords. Even so, we feel that the presence of shrunken and atrophic medial neuronal groups in this case may be significant in view of the predominantly proximal distribution of the muscle involvement with the spinal deformity and contractures of axial muscles.

The relationship of congenital fibre type disproportion to other disease states in which Type I fibre atrophy or hypotrophy is a feature has recently been the focus of extensive discussions. ${ }^{18}{ }^{24}$ Although several reports allude to a neural mechanism for the Type I fibre atrophy, there have been no clear supportive data collaborating this hypothesis. EMG evidence of neurogenic features was not corroborated in the muscle biopsy of our first two cases and findings in the diaphragm, sternomastoid and temporalis muscles of case 3 were at marked variance; the diaphragm and sternomastoid showed "dystrophic" features while there were group atrophy and fibre type aggregation in the temporalis muscle. Studies of the spinal cord in nemaline myopathy have not borne out a neurogenic concept. ${ }^{25}$ Although the injury to the cervical spinal cord does complicate the clinical picture and spinal cord abnormalities in our patient, selective atrophy and degeneration of the medial neuronal groups in the anterior horn of lumbosacral segments may represent an aetiopathologic explanation of the clinical features in this case. On the other hand, as pointed out by Robertson et al,${ }^{25}$ these neuronal changes (atrophy or smallness) may be a secondary phenomena, related to primary muscle wasting and weakness. The implications of these different clinico-pathologic features suggest the need for further studies of congenital fibre type disproportion.

The authors are grateful to Mrs Terry Murtha and the Department of Anatomy for histochemical staining of the muscle and nerve sections and the teased nerve fibre preparations and to Dr Myron Schuster, St Mary's Medical Center, Racine, Wisconsin for providing necropsy tissues of case 3 .

\section{References}

${ }^{1}$ Brooke MH. Congenital fiber type disproportion. In: Kakulas BA, ed. Clinical Studies in Myology. Proceedings of the 2nd International Congress on Muscle Diseases, Part 2. Amsterdam: Elsevier, 1973:147-59.

${ }^{2}$ De Reuck J, Hooft C, De coster W, Van den Bossche $\mathbf{H}$, Cuvelier C. A progressive congenital myopathy. Initial involvement of the diaphragm with Type I muscle fibre atrophy. Eur Neurol 1977;15:217-66.

${ }^{3}$ Reyes MG, Goldbarg H. Fiber type size disproportion in floppy infants. Annals of Neurol 1979;6:175.

${ }^{4}$ Seay AR, Ziter FA, Petajan JH. Rigid spine syndrome. A Type I fiber myopathy. Arch Neurol 1977;34:119-22.

${ }^{5}$ Goebel HH, Lenard HG, Gorke W, Kunze K. Fibre type disproportion in the rigid spine syndrome. Neuropadiatrie 1977;8:467-77.

${ }^{6}$ Clancy RR, Kelts KA, Oehlert JW. Clinical variability in congenital fiber type disproportion. J Neurol Sci 1980;46:257-66.

${ }^{7}$ Prince AD, Engel WK, Warmolts JR. Type I myofiber smallness without central nuclei or myotonia. Neurology (Minneap) 1972;22:401.

${ }^{8}$ Kinoshita M, Satoyoshi E, Kumagai M. Familial Type I fiber atrophy. J Neurol Sci 1975;25:11-17.

${ }^{9}$ Martin JJ, Clara R, Ceuterick Ch, Joris Cl. Is congenital fibre type disproportion a true myopathy? Acta Neurol Belg 1976;76:335-44.

${ }^{10}$ Lenard HG, Goebel HH. Congenital fibre type disproportion. Neuropadiatrie 1975;6:220-31.

${ }^{11}$ Brooke MH, Engel WK. The histographic analysis of human muscle biopsies with regard to fiber types. 4. Children's Biopsies. Neurology (Minneap) 1969; 19:591-605.

${ }^{12}$ Dubowitz V, Brooke MH, Neville HE. Muscle Biopsy: A modern Approach. Philadelphia: WB Saunders Company, 1973. 
${ }^{13}$ Engel WK, Cunningham CG. Rapid examination of muscle tissue. An improved trichrome method for fresh-frozen biopsy sections. Neurology (Minneap) 1963;13:919-23.

${ }^{14}$ Brooke MH, Kaiser KK. Muscle fiber types: How many and what kind? Arch Neurol 1970;23:369-79.

${ }^{15}$ Curless RG, Nelson MB. Congenital fiber type disproportion in identical twins. Ann Neurol 1977;2:455-9.

${ }^{16}$ Fardeau M, Harpey JP, Caille B. Disproportion congenitale des differents types de fibre musculaire, avec petitesse relative des fibres de Type I. Rev Neurol (Paris) 1975;131:745-66. Abstract.

${ }^{17}$ Eisler T, Wilson JH. Muscle fiber type disproportion. Report of a family with symptomatic and asymptomatic members. Arch Neurol 1978;35:823-6.

${ }^{18}$ Brooke MH, Carroll JE, Ringel SP. Congenital Hypotonia revisited. Muscle Nerve 1979;2:84-100.

19 Ringqvist M. Histochemical fiber types and fiber sizes in human masticatory muscles. Scand J Dent Res 1971;79:366-8.

${ }^{20}$ Vignon C, Pellissier JF, Serratrice G. Further histochemical studies on masticatory muscles. $J$ Neurol Sci $1980 ; 45: 157-76$.

${ }^{21}$ Crosby EC, Humphrey T, Lauer EIV. Correlative anatomy of the nervous system. New York: The Macmillan Company, 1962;72.

${ }^{22}$ Kawamura Y, O'Brien P, Okazaki H, Dyck PJ. Lumbar motoneurons of man II: The number and diameter distribution of large- and intermediate-diameter cytons in "motoneuron columns" of spinal cord of man. J Neuropath Exp Neurol 1977;36:861-70.

${ }^{23}$ Kawamura Y, Dyck PJ. Lumbar motoneurons of man III: The number and diameter distribution of large- and intermediate-diameter cytons by nuclear columns. $J$ Neuropath Exp Neurol 1977:36:956-63.

${ }^{24}$ Engel WK. Muscle fiber hypotrophy with central nuclei. In: Goldensohn ES, Appel SH, eds. Scientific Approaches to Clinical Neurology. Philadelphia: Lea \& Febiger, 1977:1572-600.

${ }^{25}$ Robertson WC Jr, Kawamura Y, Dyck PJ. Morphometric study of motoneurons in congenital nemaline myopathy and Werdnig-Hoffmann disease. Neurology (Minneap) 1978;28:1057-61. 